\title{
Long-term effectiveness of the Midwifery Initiated Oral Health-Dental Service Program on maternal oral health knowledge, preventative dental behaviours and the oral health status of children in Australia
}

\author{
Ajesh George ( $\sim$ a.george@westernsydney.edu.au ) \\ Western Sydney University \\ Ariana Kong \\ Western Sydney University \\ Mariana Sousa \\ Western Sydney University \\ Amy Villarosa \\ Western Sydney University \\ Shilpi Ajwani \\ Sydney Dental Hospital \\ Hannah Dahlen \\ Western Sydney University \\ Sameer Bhole \\ Sydney Dental Hospital \\ Albert Yaacoub \\ Nepean Blue Mountains Local Health District \\ Ravi Srinivas \\ South Western Sydney Local Health District \\ Maree Johnson \\ Australian Catholic University
}

\section{Research Article}

Keywords: Oral health, dental decay, caries, pregnancy, mother

Posted Date: August 3rd, 2021

DOI: https://doi.org/10.21203/rs.3.rs-723870/v2

License: (c) (i) This work is licensed under a Creative Commons Attribution 4.0 International License. Read Full License 


\section{Abstract \\ Background}

Early childhood caries remains a public health challenge and many interventions to manage this disease have focused on prevention during early infancy. Promoting oral health during pregnancy may also improve the oral health of children, however, there is limited evidence in Australia. The Midwifery Initiated Oral Health-Dental Service (MIOH-DS) was developed to train midwives to promote maternal oral health and a large trial showed the program substantially improved the oral health status, knowledge and behaviours of pregnant women. This study evaluated the long-term effectiveness of the program (post trial) on maternal oral health knowledge, preventative dental behaviours, and early childhood caries in offspring.

\section{Methods}

A prospective cohort study was conducted in three large metropolitan health services in Sydney, Australia. The study followed 204 women and their children three to four years after participating in the original MIOH-DS trial (intervention and control groups). The outcome measures included child dental decay (cariogenic bacteria), and a maternal oral health knowledge and behaviours questionnaire. Descriptive statistics were used to analyse the main outcomes and a regression model was constructed to explore predictors of dental decay among children.

\section{Results}

There were no significant differences across the outcome measures between the MIOH-DS participants (mother/child) and control groups except for a small difference in maternal oral health knowledge. Most mothers across both groups demonstrated high oral health knowledge and positive oral health practices, and the regression model found that these outcomes provided a protective effect (low levels of bacteria and dental caries) among children. Some aspects of oral health remained poorly understood by mothers across both groups-the oral health impact of sugary foods and drinks, at-risk feeding practices, and the recommended age for first dental visits.

\section{Conclusions}

The long-term impact of the program demonstrates the effectiveness of improving maternal oral health knowledge and preventative behaviours to reduce the risk of early childhood caries, although the specific effect of the $\mathrm{MIOH}$ DS program was not found. Although oral health knowledge was high across participants the findings suggest the need for reinforced education around feeding, diet and dental visiting through postnatal early childhood services to show sustained improvements.

\section{Background}

The initiation of dental caries is a complex process where the presence of dental bacteria, specifically high levels of Streptococcus mutans and lactobacilli, have been associated with commencing and advancing dental decay [1, 2]. The presence of high sucrose levels accelerates this process as the dental biofilm and bacteria shift to 
metabolise sugars, increase acidity, and create an environment conducive to caries development [3]. Early childhood caries (ECC), defined as presence of at least one carious lesion in children under 6 years of age, is a common chronic disease that affects children globally. Many countries across the world report a prevalence of more than $50 \%$ of ECC among children, and up to $90 \%$ in some regions, by the age of five [4]. In Australia around $42 \%$ of preschool children experience decay in their primary teeth [5]. ECC can affect a child's quality of life in the short term, and impede speech, cognitive, psychological, and physical development over the long term [6]. The dental treatments for ECC can be costly [7] and delays in treatment can exacerbate the child's poor oral health, potentially resulting in the need for more extensive dental treatment including hospitalisation [8]. ECC has also been found to be a predictor of future dental carries in permanent teeth [9].

Although ECC is a multifactorial disease, its onset and progression in children can be mitigated through costeffective educational interventions for parents and children around oral hygiene practices as early as before birth and when feeding [10]. Many interventions that have been designed to manage ECC are focused on the early infancy period (around 0-2 years). The World Health Organization suggested that strategies should include a caries risk assessment by the child's first year and preventive measures such as behavioural management (oral hygiene, diet and the use of fluoridated toothpaste) [11].

Pregnancy is a period where mothers are more amenable to changes in health behaviours. Thus targeted oral health educational interventions during pregnancy, especially among mothers with fewer educational qualifications, could increase the effectiveness of existing interventions to reduce dental decay for children during early infancy [12]. One Cochrane review found that although giving feeding and dietary advice to pregnant women and mothers likely results in a small reduction in ECC, this review did not focus on the role of antenatal care providers [13]. Previous studies have demonstrated that antenatal care providers can effectively promote oral health through education, risk assessment and referrals among pregnant women [14-19]. To date, only one study conducted in the United States has followed up children from an oral health intervention during pregnancy involving non-dental professionals like nurses [20]. Larsen et al. [20] followed the cohort of children $(n=91)$ to assess the program's effectiveness in improving oral health outcomes. Children of the mothers who were part of the program, were found to have had fewer dental caries and extractions after three years.

In Australia, however, there are currently no studies evaluating the effectiveness of an antenatal intervention delivered during antenatal care in reducing the incidence of dental caries among children [21]. The Midwifery Initiated Oral Health-Dental Service (MIOH-DS) program was the first model of care in Australia where midwives were trained through an online platform to promote oral health among pregnant women [17]. This model involved training midwives in providing oral health education, performing an oral health screening assessment and following clear referral pathways to dentists. The model was designed so that antenatal care providers could raise awareness about the importance of oral health during an antenatal appointment with a woman, undertake a risk assessment, and connect them with a dental service [17]. A multi-centre randomised controlled trial $(n=638)$ found that the model significantly improved the rate of pregnant women accessing a dentist, the mother's oral health and knowledge about appropriate oral health practices during pregnancy and in early childhood [22]. However, further research is needed to assess its effectiveness in maintaining the knowledge and practices in the long-term and reducing ECC among the children of mothers who received this intervention during pregnancy.

\section{Methods}




\section{Research aims and hypotheses}

The aim of this study was to establish whether the MIOH-DS program, is an effective antenatal intervention to: (i) maintain long-term maternal oral health knowledge and behaviours (ii) enhance infant oral health. This longitudinal study involved following up women and their children, who had participated in the MIOH-DS program multicentre trial [22]. The specific aims were to determine the impact of the MIOH-DS program on:

- Mothers' knowledge retention in oral health care of their children

- Preventative dental behaviours (dentist visits, oral hygiene, eating and feeding habits) among their children aged between three to four years

- Prevalence of cariogenic bacteria and dental decay among children (ECC)

It was hypothesised that women who received the MIOH-DS program would demonstrate sustained improvement in knowledge regarding oral health care for their children. It was also hypothesised that the children of the women who received the MIOH-DS intervention program would have improved preventative dental behaviours and reduced prevalence of ECC.

\section{Study design}

A prospective cohort study design was used to follow up the children of mothers who were part of the MIOH-DS multicentre trial. The reporting for this study was guided by the STROBE statement, a checklist for cohort studies [23].

\section{Setting}

The study was conducted between 2017 to 2019 across three large metropolitan health services within Greater Western Sydney (GWS) region in New South Wales (NSW), Australia where the MIOH-DS trial was undertaken. The GWS region is the residence of over 2.5 million people and is the third largest economy in Australia [24]. Compared to other regions of Sydney, however, GWS residents experience slightly higher rates of unemployment and have a smaller proportion of households with higher income [25].

\section{Participants}

Participants included mothers who participated in the MIOH-DS trial (any group) and their child. Mothers were purposively sampled according to the group they were allocated to in the trial. Specifically, this study followed up mothers and children from the intervention groups who received the MIOH-DS program (midwives providing oral health education, assessment and referrals to a designated public dental service clinic), the $\mathrm{MIOH}$ program (midwives providing oral health education, assessment and referrals to existing services - public dental service/private dentist/health fund), and the control group who did not receive the MIOH-DS/MIOH program but did receive an oral health promotional brochure [26]. The electronic medical records were checked to exclude mothers who had adverse pregnancy outcomes such as miscarriage. As part of current NSW state health department practice all children had access to the early childhood oral health $(\mathrm{ECOH})$ program (oral health education, assessment and referrals provided by child health professionals) during their child health checks (6-8 months, 12 months, 18 months, 2, 3 and 4 years of age) [27].

\section{Sampling and recruitment}


All women in the MIOH-DS trial were invited to participate. It was expected that $30 \%$ [26] would not be contactable or lost to follow-up (due to incorrect or disconnected telephone number) and a further $10 \%$ would refuse participation. Therefore, a total of 398 contactable women were potentially able to join this longitudinal follow-up. The medical record numbers of mothers who could not be contacted were supplied to the data custodians of the electronic medical records system and obstetric database, to assist in locating updated contact details.

Flyers advertising the study along with information sheets, a checklist and reply-paid envelopes, were sent to mothers inviting their attendance with their child (when aged 3-4 years) to a free dental check-up and treatment (if required), at a nearby public dental service. Interested mothers could opt-into the study by contacting the project team directly via phone or using the checklist and reply-paid envelopes provided. Follow-up calls were made after two weeks of no response.

Interested mothers completed a survey and had a dental appointment booked for their child. As part of current practice all children in NSW under the age of 18 years have access to free dental assessments and treatment through the public dental services [28].

\section{Study measures}

The study measures included maternal oral health knowledge, preventative dental behaviours (eating and feeding habits, oral hygiene, and dental visits), prevalence of cariogenic bacteria and dental decay among children.

\section{Data collection}

Data were collected across the span of one year when the child was between three to four years old. It involved collecting dental assessment data from the child, administering questionnaires to mothers and verifying if the participant had received the ECOH program. The medical record numbers (MRNs) of the mother and child were used to link the various data. Data for both intervention and control groups were collected in the same way.

The child's dental decay was assessed by qualified and trained dental/oral health therapists using the validated decayed-missing-filled teeth (dmft)/decayed-missing filled surface (dmfs) index [29] and a Caries Risk Test kit [30] which provided a count of cariogenic bacteria in the saliva (Streptococcus mutans/lactobacilli). The dmft index is the sum of the total number of decayed, missing due to caries, and filled teeth in the child's mouth and ranges from 0 to 20 [29]. The mean dmft is the sum of individual dmft values divided by the total number of children examined. The caries risk test assesses the bacterial count as either $<10^{5}$ (negative for Streptococcus mutans/lactobacilli) or $>10^{5}$ (positive for Streptococcus mutans/lactobacilli). Prior to the study six dental/oral health therapists were trained and calibrated by senior clinicians on the $\mathrm{MIOH}$ team to follow a standardised dental protocol during the oral assessments. More than $80 \%$ inter-rater reliability was achieved after training.

A questionnaire was administered to mothers when the child was between 3-4 years old via telephone or at their child's dental appointment. It assessed the self-reported oral health status, oral hygiene habits, uptake of dental services, diet, feeding practices, dental-related hospitalisations of the child, and oral health knowledge of the parent (see Supplementary File 1). Demographic data were also collected to complement the existing data collected from the MIOH study. The questionnaire was pilot tested with a small sample of mothers and included validated (self-reported oral health status, uptake of dental services and previously tested items (oral hygiene habits, oral health knowledge) [26].

\section{Statistical methods}


Data were analysed using the IBM SPSS Statistics software, version 22. Demographics were analysed with descriptive statistics and frequencies. The categorical data yielded from the caries risk tests were analysed using chi-squared statistics. Data obtained from the questionnaire regarding preventative dental behaviours and oral health care knowledge were in the format of Likert-type scales and frequencies and were analysed using cross tabulations and chi-square statistics. Due to the lack of dental intervention in the $\mathrm{MIOH}$ group, this group was combined with the control group for group comparisons, thus analyses compared participants from the MIOH-DS group with participants from either the $\mathrm{MIOH}$ or control group. The differences in proportions for the caries risk tests between the groups were analysed using odds ratios. The mean dmft for each group was compared using distribution-free tests such as Mann-Whitney U tests. After inspection of untransformed variables using crosstabulations or correlation matrices as appropriate, logistic regression was undertaken to identify predictors of having a dmft score of one or more. Variables entered into this model included dietary habits related to sugar consumption, oral health behaviours such as sharing eating utensils, using mouth to clean pacifier, coating pacifier with sweet substances or giving a bottle when child is lying down to sleep, MIOH-DS group participant or not $(1,0)$ and whether the mother received information about child oral health. Nagelkerke R-Square and Hosmer Lemeshow goodness-of-fit tests were used to explore the model fit.

\section{Ethical considerations}

Informed written and verbal consent was obtained from parents at the time of the appointment. The study was approved by the South Western Sydney Local Health District Human Research Ethics Committee (HE16/225). The study was conducted in accordance with the ethical principles of the Declaration of Helsinki.

\section{Results}

\section{Recruitment and Demographics}

Of the 638 mothers who were part of the MIOH-DS trial, 204 women were followed up and completed the questionnaire (31.9\% response rate, 136 (66.7\%) from MIOH/control groups, 68 (33.3\%) from MIOH-DS group). Among the 435 mothers who did not participate, 162 (37.0\%) were lost to follow up, 171 (39.3\%) declined participation, 98 (22.5\%) moved out of the study area and 4 (0.9\%) experienced pregnancy loss. Most respondents who agreed to participate?? $(n=166,81.2 \%)$ agreed for their children $(n=169)$ to receive an oral health assessment. Three of the mothers whose children received an oral health assessment had twins. Respondents were $33.56 \pm$ 5.18 (SD) years old on average, most were born in Australia (62.7\%) and spoke English only at home (71.1\%). About half (47.8\%) were not working at the time of the survey. A majority of respondents (78\%) had either vocational or university education. (Table 1)

\section{Table 1: Demographic characteristics of respondents $(n=204)$}




\begin{tabular}{|c|c|}
\hline Variables & $\mathrm{n}(\%)$ \\
\hline \multicolumn{2}{|l|}{ MIOH group } \\
\hline $\mathrm{MIOH} /$ control & $136(66.7)$ \\
\hline MIOH-DS & $68(33.3)$ \\
\hline $\begin{array}{l}\text { Age in years, mean [median] (SD) } \\
\text { (range, 22-50) }\end{array}$ & $33.56[32.96](5.18)$ \\
\hline \multicolumn{2}{|l|}{ Country of birth } \\
\hline Australia & $128(62.7)$ \\
\hline Overseas & 76 (37.3) \\
\hline \multicolumn{2}{|l|}{ Language spoken at home } \\
\hline English only & $145(71.1)$ \\
\hline English and another language & $35(17.2)$ \\
\hline Language other than English & $24(11.8)$ \\
\hline \multicolumn{2}{|l|}{ Parity } \\
\hline Primipara & $34(16.7)$ \\
\hline Multipara & 170 (83.3) \\
\hline \multicolumn{2}{|l|}{ Employment status ( $n=203$ ) } \\
\hline Working full-time & 40 (19.7) \\
\hline Working part-time & $66(32.5)$ \\
\hline Not working & $97(47.8)$ \\
\hline \multicolumn{2}{|l|}{ Highest educational qualification } \\
\hline Secondary school & $24(11.8)$ \\
\hline High school & $21(10.3)$ \\
\hline Vocational education & $105(51.5)$ \\
\hline University & $54(26.5)$ \\
\hline \multicolumn{2}{|l|}{ Marital Status } \\
\hline Single & 39 (19.1) \\
\hline Married/Partnered & 159 (77.9) \\
\hline Divorced & $6(2.9)$ \\
\hline \multicolumn{2}{|l|}{ Average fortnightly household income } \\
\hline$<\$ 700$ & $4(2.0)$ \\
\hline$\$ 700-\$ 1,200$ & 32 (15.7) \\
\hline$\$ 1,200-\$ 2,000$ & 38 (18.6) \\
\hline$\$ 2,000-\$ 3,000$ & $35(17.2)$ \\
\hline$>\$ 3,000$ & 34 (16.7) \\
\hline Don't know & $43(21.1)$ \\
\hline Refused & $18(8.8)$ \\
\hline Had private health insurance & $68(33.3)$ \\
\hline Had concession/Health Care Card ( $n=199)$ & $87(42.6)$ \\
\hline Child attending daycare/pre-school $(n=203)$ & $168(82.8)$ \\
\hline
\end{tabular}

\section{Oral health knowledge of mothers}

Overall, participants ( $n=176$ ) had high knowledge scores, with an average score of $21.77 \pm 2.70$ out of a total of 26 points. The higher proportions of incorrect responses were seen on items related to risk factors for tooth decay such as lack of calcium ( $89 \%$ ) and sugary snacks at mealtimes $(78 \%)$ as well as the recommended age for a child's first dental visit (69\%) (Table 2). There was a small yet significant difference in total knowledge score between MIOH-DS and control groups (22.51 in MIOH-DS vs 21.39 in control, Mann-Whitney U=2710.5, p=0.029). Most significant differences were seen for knowledge regarding putting baby to bed with bottles of milk, performing regular 'lift the lip' checks, rinsing after meals, and sipping sweet beverages from bottles/cups throughout the day (see Supplementary File 2). 
[Insert Table 2 here]

Table 2: Oral health knowledge items and proportion of correct responses (CR)

\section{Preventative dental behaviours}

\section{Dental visits}

Of the mothers who had some concern with their child's teeth (25.0\%), about half (49.0\%) visited a dental professional for this problem. Less than half, reported regularly taking their child to a dentist each year (46.0\%), and only about a third (36.3\%) reported that their child saw a dentist in the last 12 months. Only $23.6 \%$ of mothers reported their children having their first dental visit at or before the age of one. Most children who had visited the dentist last saw a dentist in a private dental practice $(65.0 \%)$ or a governmental dental clinic (18.8\%). A small proportion of children (4\%) were hospitalised for dental problems. See Table 3 for full dental visit data.

Although more than half of respondents received information about oral health care during early childhood (61.7\%), few (1.6\%) received the $\mathrm{ECOH}$ program at child health checks. A significant relationship was found between intervention and control groups whereby those who were in the $\mathrm{MIOH}$ intervention group were more likely to have received information about oral health care for their child by the time of this study $(p<0.04)$.

\section{Oral hygiene}

Most mothers reported that their child's teeth were brushed once or twice a day (92.1\%). A majority of participants used children's toothpaste for their child's teeth (85.2\%), followed by standard fluoride toothpaste (9.9\%). Almost all (98.0\%) mothers usually assisted their child to brush their teeth. Most respondents (83.3\%) applied toothpaste and brushed their child's teeth. The majority (67.8\%) of parents reported usually using a pea-sized amount of toothpaste on their child's toothbrush. There were no significant differences in these practices between groups.

\section{Eating and feeding habits}

Just over a quarter (27.6\%) of mothers reported their child consuming juice at least once a day. A similar proportion (25.1\%) reported their child consuming biscuits, cakes donuts or muesli bars, at least once per day. Fewer mothers reported at least daily consumption of confectionary (10.9\%), or soft drink (3.0\%). 
A third of participants reported that their child currently uses a bottle (31.4\%), and most reported that their child used a feeder cup (81.4\%). More than two-thirds of participants identified that their child always drinks from a regular cup (68.1\%). Just under half of mothers reported that their child $(41.7 \%)$ regularly used a pacifier at some point in their lives. Most parents reported having practised, or currently practising, sharing utensils while feeding their child (60.3\%). Some mothers reported giving their child a bottle when lying down to rest (40.2\%), using their mouth to clean a pacifier for their child (12.7\%), or coating a pacifier or bottle tea with honey or other sweet substance (3.4\%), at some point. Cup usage was the only variable that varied significantly across groups, with $19.4 \%$ more mothers in the MIOH-DS group reporting their child always drank from a cup (Pearson's $\chi^{2}=11.734$, $p=0.019$ ) (see Supplementary File 2).

[Insert Table 3 here]

Table 3: Child preventative dental behaviours as reported by mothers

\section{Dental decay among children}

Less than half of mothers (43.6\%) perceived their child's oral health to be "very good".

A quarter of mothers (25.0\%) reported to have some concern with their child's teeth, gums, or mouth. (Table 4) No significant relationship was found between intervention and control groups. These women reported the following concerns: cavities $(10.8 \%)$, toothache $(1.5 \%)$, broken teeth $(1.0 \%)$, bleeding gums $(0.5 \%)$, loose teeth $(0.5 \%)$ or other problems (12.7\%).

The oral assessment found that overall, the 169 children who were assessed, had good oral health, with the mean dmfs and dmft being 0.66 and 0.56 respectively (Table 5). Of these children, only $15.5 \%$ tested positive for Streptococcus mutans and $15.9 \%$ tested positive for lactobacilli (See Table 4). This also did not vary significantly between intervention and control groups.

\section{Table 4: Child characteristics and oral assessment}




\begin{tabular}{lr}
\hline \multicolumn{1}{c}{ Variable } & \multicolumn{1}{c}{$\mathbf{n}(\%)$} \\
\hline Age (mean \pm SD [median]) & $4.07 \pm 0.41[3.92]$ \\
Parent reported concerns with child's oral health & $51(25.0)$ \\
Parent perception of child oral health & \\
Very good & $89(43.6)$ \\
Good & $23(41.7)$ \\
Average & $7(3.4)$ \\
Poor & $32(15.5)$ \\
Streptococcus mutans positive & $33(15.9)$ \\
Lactobacilli positive & $0.56 \pm 1.31[0]$ \\
dmft (mean \pm SD [median]) & $0.66 \pm 1.87[0]$ \\
dmfs (mean \pm SD [median]) & $37(21.9)$ \\
dmft at least 1 & \\
\hline Dmft $\geq 1$ indicates any child who had at least one decayed, missing or filled tooth.
\end{tabular}

\section{Relationships with dmft}

Initial crosstabulations and a correlation matrix were conducted to inform a logistic regression model constructed to determine variables associated with dental decay among children (see Supplementary File 3). Variables were selected for this model on the basis of the research aims, potential to be confounding variables, as well as statistically significant associations at $p<0.05$.

The final regression model found mothers' oral health knowledge scores at the end of the MIOH-DS trial, and coating pacifiers or teats with sweet substances to be significantly associated with their child's dmft at the time of assessment (Table 5). With each additional knowledge score point at the end of MIOH-DS trial, the odds of having a dmft of one or more were reduced by almost half (OR 0.581). Conversely, coating a pacifier or teat with sweet substances increased the odds of a dmft of one or more by over 15 times (OR 15.073). There was also a trend whereby children who consumed soft drink at least once per day had over ten times the odds of having a dmft greater than 1, however this was non-significant (OR 10.690). This model was shown to have good fit, with a Hosmer and Lemeshow goodness of fit test yielding a non-significant result (Table 5).

Table 5: Regression model of determinants of having a dmft score of 1 or more $(n=138)$ 


\begin{tabular}{|c|c|c|c|c|c|c|}
\hline \multirow[t]{2}{*}{ Covariate } & \multirow[t]{2}{*}{$\begin{array}{l}\text { Odds } \\
\text { Ratio } \\
(\exp (\mathrm{B}))\end{array}$} & \multirow[t]{2}{*}{$\begin{array}{l}\text { Standard } \\
\text { Error }\end{array}$} & \multirow[t]{2}{*}{ Wald } & \multicolumn{2}{|c|}{$\begin{array}{l}\text { 95\% Confidence } \\
\text { Interval for Odds } \\
\text { Ratio }\end{array}$} & \multirow[t]{2}{*}{$p$ value } \\
\hline & & & & Lower & Upper & \\
\hline $\begin{array}{l}\text { Child consumes juice at least once a } \\
\text { day }\end{array}$ & 1.513 & 0.561 & 0.545 & 0.504 & 4.538 & 0.460 \\
\hline $\begin{array}{l}\text { Child consumes soft drink at least } \\
\text { once a day }\end{array}$ & 10.690 & 1.331 & 3.170 & 0.788 & 145.085 & 0.075 \\
\hline $\begin{array}{l}\text { Child consumes biscuits, cakes, } \\
\text { donuts or muesli bars at least once a } \\
\text { day }\end{array}$ & 1.646 & 0.576 & 0.749 & 0.533 & 5.085 & 0.387 \\
\hline $\begin{array}{l}\text { Child consumes confectionery at } \\
\text { least once a day }\end{array}$ & 0.941 & 0.905 & 0.005 & 0.160 & 5.547 & 0.946 \\
\hline Shares eating utensils with child & 1.281 & 0.535 & 0.215 & 0.449 & 3.656 & 0.643 \\
\hline $\begin{array}{l}\text { Used mouth to clean pacifier for } \\
\text { child }\end{array}$ & 0.663 & 0.782 & 0.277 & 0.143 & 3.070 & 0.599 \\
\hline $\begin{array}{l}\text { Coated pacifier or teat with sweet } \\
\text { substances }\end{array}$ & 15.073 & 1.103 & 6.045 & 1.734 & 131.047 & 0.014 \\
\hline $\begin{array}{l}\text { Given a bottle when lying down to } \\
\text { sleep }\end{array}$ & 0.686 & 0.543 & 0.482 & 0.237 & 1.988 & 0.487 \\
\hline Knowledge score post MIOH-DS & 0.581 & 0.250 & 4.722 & 0.355 & 0.948 & 0.030 \\
\hline MIOH-DS vs MIOH/Control groups & 0.579 & 0.547 & 0.998 & 0.198 & 1.692 & 0.318 \\
\hline $\begin{array}{l}\text { Mother received information about } \\
\text { child oral health }\end{array}$ & 2.311 & 0.560 & 2.240 & 0.772 & 6.920 & 0.134 \\
\hline $\begin{array}{l}\text { Constant } \\
\text { Nagelkerke R Square } \\
\text { Hosmer and Lemeshow test }(p ; \mathrm{df})\end{array}$ & 11.494 & 2.110 & 1.339 & & & $\begin{array}{r}0.247 \\
.233310 \\
0.708 ; 8 \\
\end{array}$ \\
\hline
\end{tabular}

\section{Discussion}

This is the first study that has evaluated the long-term oral health outcomes in infants of mothers who received a comprehensive oral health program delivered by antenatal care providers during pregnancy. Results revealed that high maternal oral health knowledge provided a protective effect for dental decay in children. This protective effect supports guidelines that recommend the delivery of oral health education to mothers as early as during pregnancy $[31,32]$.

Overall, the participants demonstrated high levels of oral health knowledge and positive oral health practices. Almost all women could correctly identify items such as dental caries as a disease, the impact of undetected tooth decay and the appropriate amount of toothpaste required for children. Furthermore, the high rates of toothbrushing and appropriate usage of fluoridated products for children may be comparable to other studies conducted in highincome countries [33,34]. There was a small but significant difference in maternal oral health knowledge in the intervention group which is an improvement from all previous studies that have found no change [14, 15]. Further, the intervention group did have better knowledge about key risk factors for early childhood caries such as putting the baby to bed with a bottle and sipping sweet beverages from bottles/cups as well preventative strategies like performing regular oral health checks (lift the lip). Given the control group in our study also received an educational oral health brochure during pregnancy which is unique, this result suggests that in the long-term, any form of early childhood oral health education antenatally is valuable and may contribute to higher maternal oral heath knowledge post birth.

While knowledge scores were high overall, there were some aspects of oral health that were not very well understood by the mothers and which require further attention. For instance, items related to feeding practices and 
dental visits. This has also been identified as a gap in oral health knowledge by Blinkhorn et al. [35]. They found that although mothers had an understanding about good oral health practices, only $7 \%$ of mothers could identify the foods and drinks that contained the most sugar [35]. Understanding the oral health impact of sugar consumption is important as caregivers tend to have greater intention to limit sugary foods and drinks they offer to their child, when higher knowledge is evidenced [36]. Further, although it was not asked as a knowledge item, clearly the fact that some mothers reported coating their child's pacifier in a sugar sweetened substance, sharing utensils while feeding and giving a bottle to the baby while lying down, highlights a knowledge gap in these areas. Some studies have suggested that health advice from clinicians can assist to educate and remind parents about these feeding behaviours [37]. Reinforcement of oral health education postnatally could strengthen the impact seen with our intervention. One hypothesis for some gaps in knowledge/behaviour found in this study could be associated with the fact that the $\mathrm{MIOH}-\mathrm{DS}$ program was delivered antenatally. In the $\mathrm{ECOH}$ program, delivered postnatally, certain feeding and dietary behaviours are typically reinforced through child health professionals; however, in this sample, very few mothers received the $\mathrm{ECOH}$ program for their child. Previous reported data on the $\mathrm{MIOH}-\mathrm{DS}$ program also showed that oral health outcomes and knowledge among pregnant women were improved in the short term only [22]. In fact, changes in oral health knowledge appeared to diminish during the follow up period.

The need for postnatal education was recently noted by a review conducted by George et al. [21]. This work suggested that a combined intervention across both the antenatal and postnatal periods may deliver results in improved oral health outcomes among children. Other avenues of support such as general practitioners, maternal and early childhood services, pharmacies and childcare services may need to be considered to reinforce some of the key knowledge gaps identified in this study. Another avenue for education could be on packaging that surrounds pacifiers, infant bottles and baby spoons.

About $50 \%$ of children in our sample had seen a dentist by the age of two, but only a few had seen the dentist by the recommended age of one. This is a relatively better outcome than what is reported in the Australia's national dental telephone survey, which found that about $30 \%$ of children aged 2 to 4 years, had seen the dentist [38]. While this is not a direct comparison, this statistic suggests that raising oral health awareness during pregnancy through programs like the MIOH-DS may positively affect some mothers' decision to access dentists for their children earlier. Strategies that have the potential to change intention to see the dentist and thus, improve dental visits are a very important step towards diminishing the ECC inequality. This has recently been suggested by Peres et al. [39]'s findings from the analysis of a National Child Oral Health Survey conducted in Australia. The need for timely messages about seeing the dentist is also supported by literature in other high-income countries, which have found that caregivers may not book dental appointments by the recommended age due to lack of awareness or misinformation [40-42]. Thus, reinforcing the need for educational interventions on dental visits during the postnatal and early childhood period.

The proportion of participants reporting access to public dental clinics in our study was similar to national reported data (19.4\%) among children aged 2-4 years [38]. Reasons for accessing public oral health services were not explored in this study; however, various other Australian surveys have found that about $30 \%$ of parents were not aware that their child was eligible for free dental services [43,44]. Only about half of parents in Queensland are aware of the Child Dental Benefits Schedule that subsidises the cost of preventative or general dental treatment for children in public or private practices [43]. In NSW, information about eligibility to free dental services could be reinforced postnatally during the established $\mathrm{ECOH}$ program. 
The strengths of this study include prospectively collected data in a large cohort using validated measures. The limitations include the long latency period before the follow up. This may have contributed to the low response rate; many participants had moved away or changed contact details. Similarly, this loss to follow-up of women may have contributed to selection bias. Although the $\mathrm{ECOH}$ program is recommended state-wide, very few women in this study, received the program for their children. Consequently, it is difficult to ascertain the impact of the $\mathrm{ECOH}$ program on early childhood oral health when combined with an antenatal oral health intervention.

\section{Conclusions}

The long-term impact of the MIOH-DS program demonstrates the importance of improving maternal oral health knowledge during pregnancy to reduce the risk of children developing early dental decay. Our findings also further support the role of antenatal care providers in promoting oral health as a part of a healthy pregnancy. Although the oral health knowledge among the mothers was high generally, the study suggests that oral health education around feeding, diet, and dental visiting requires reinforcement during the postnatal period to bring about longterm behaviour change along with sustained improvements and innovative ways may need to be tested to find the best strategy. Future research should explore the long-term impact of an antenatal and postnatal oral health intervention on the oral health of children in children. Such strategies would align with the Australian governments focus on preventative initiatives across pregnancy and first 2000 days [45].

\section{List Of Abbreviations}

decayed-missing filled surface (dmfs); decayed-missing-filled teeth (dmft); early childhood caries (ECC); early childhood oral health (ECOH) program; Greater Western Sydney (GWS); medical record numbers (MRNs); Midwifery Initiated Oral Health-Dental Service (MIOH-DS); New South Wales (NSW)

\section{Declarations}

\section{Ethics approval and consent to participate.}

This study has been approved by the South Western Sydney Local Health District Human Research Ethics Committee (HREC/16/LPOOL/418). Reciprocal approval was also granted from Western Sydney University (HE16/225). Participating in the study was voluntary and informed written and verbal consent was obtained from all participants.

\section{Consent for publication}

Not applicable.

\section{Availability of data and materials}

The dataset used during the current study are available from the corresponding author on reasonable request.

\section{Competing interests}


The authors declare that they have no competing interests.

\section{Funding}

This study was funded by the Financial Markets Foundation for Children. The funding body had no role in the study design, data collection, analysis and in drafting the manuscript.

\section{Authors' contributions}

$A G$ and $M J$ were involved in the conceptualisation and design of the study. AG, AK, MS and MJ designed and wrote the first draft of the manuscript. Additionally, AG, AK and MS coordinated the data collection. AV and MJ assisted with data analysis and had the complete access to the data. AG, AK, MS, AV, SA, SB, HD, AY, RS and MJ assisted with data interpretation. All the authors contributed to the subsequent versions of the manuscript and approved the final version for submission.

\section{Acknowledgements}

We would like to thank the dental team (dental/oral health therapists and dental assistants) from South Western Sydney Local Health District and Nepean Blue Mountains Local Health District who completed the oral health assessments of the children. We would also like to thank Dental Assistant, Diana Wiskich who supported the recruitment of participants and data collection.

\section{References}

1. Caufield PW, Schön CN, Saraithong P, Li Y, Argimón S. Oral Lactobacilli and Dental Caries: A Model for Niche Adaptation in Humans. J Dent Res. 2015;94(9 Suppl):110s-8s.

2. Thenisch NL, Bachmann LM, Imfeld T, Leisebach Minder T, Steurer J. Are Mutans Streptococci Detected in Preschool Children a Reliable Predictive Factor for Dental Caries Risk? A Systematic Review. Caries Research. 2006;40(5):366-74.

3. Metwalli KH, Khan SA, Krom BP, Jabra-Rizk MA. Streptococcus mutans, Candida albicans, and the Human Mouth: A Sticky Situation. PLOS Pathogens. 2013;9(10):e1003616.

4. Chen KJ, Gao SS, Duangthip D, Lo ECM, Chu CH. Prevalence of early childhood caries among 5-year-old children: A systematic review. Journal of investigative and clinical dentistry. 2019;10(1):e12376.

5. Australian Institute of Health Welfare. Australia's children [Internet]. Canberra: AlHW; 2020 [cited 2011 July 7]. Available from: https://www.aihw.gov.au/reports/children-youth/australias-children.

6. Colak H, Dülgergil CT, Dalli M, Hamidi MM. Early childhood caries update: A review of causes, diagnoses, and treatments. J Nat Sci Biol Med. 2013;4(1):29-38.

7. Tonmukayakul U, Arrow P. Cost-effectiveness analysis of the atraumatic restorative treatment-based approach to managing early childhood caries. Community dentistry and oral epidemiology. 2017;45(1):92-100. 
8. Australian Institute of Health and Welfare. Oral health and dental care in Australia [Internet]. Canberra: AlHW; 2021 [cited 2021 May 26]. Available from: https://www.aihw.gov.au/reports/dental-oral-health/oral-healthand-dental-care-in-australia.

9. Songur F, Simsek Derelioglu S, Yilmaz S, Koşan Z. Assessing the impact of early childhood caries on the development of first permanent molar decays. Front Public Health. 2019;7:186-.

10. Samnaliev M, Wijeratne R, Grace Kwon E, Ohiomoba H, Wai Ng M. Cost-effectiveness of a disease management program for early childhood caries. Journal of Public Health Dentistry. 2015;75(1):24-33.

11. World Health Organisation. WHO expert consultation on public health intervention against early childhood caries: report of a meeting. Bangkok, Thailand: WHO; 2017.

12. Crozier SR, Robinson SM, Borland SE, Godfrey KM, Cooper C, Inskip HM, Group SWSS. Do women change their health behaviours in pregnancy? Findings from the Southampton Women's Survey. Paediatr Perinat Epidemiol. 2009;23(5):446-53.

13. Riggs E, Kilpatrick N, Slack-Smith L, Chadwick B, Yelland J, Muthu MS, Gomersall JC. Interventions with pregnant women, new mothers and other primary caregivers for preventing early childhood caries. The Cochrane database of systematic reviews. 2019;2019(11).

14. Adams SH, Gregorich SE, Rising SS, Hutchison M, Chung LH. Integrating a Nurse-Midwife-Led Oral Health intervention Into CenteringPregnancy Prenatal Care: Results of a Pilot Study. Journal of midwifery \& women's health. 2017;62(4):463-9.

15. Cibulka NJ, Forney S, Goodwin K, Lazaroff P, Sarabia R. Improving oral health in low-income pregnant women with a nurse practitioner-directed oral care program. Journal of the American Academy of Nurse Practitioners. 2011;23(5):249-57.

16. Deshpande A, Dhillon S, Poonacha K, Dave B, Porwal P, Macwan C. Impact of perinatal oral health care education programme on the knowledge, attitude and practice behavior amongst gynaecologists of Vadodara city. 2015;33(2):122-7.

17. George A, Lang G, Johnson M, Ridge A, de Silva AM, Ajwani S, Bhole S, Blinkhorn A, Dahlen HG, Ellis S, Yeo A, Langdon R, Carpenter L, Heilbrunn-Lang A. The evaluation of an oral health education program for midwives in Australia. Women and Birth. 2016;29(3):208-13.

18. Heilbrunn-Lang AY, de Silva AM, Lang G, George A, Ridge A, Johnson M, Bhole S, Gilmour C. Midwives' perspectives of their ability to promote the oral health of pregnant women in Victoria, Australia. BMC Pregnancy and Childbirth. 2015;15(1):110.

19. Villarosa AC, Villarosa AR, Salamonson Y, Ramjan LM, Sousa MS, Srinivas R, Jones N, George A. The role of indigenous health workers in promoting oral health during pregnancy: a scoping review. BMC Public Health. 2018;18(1):381.

20. Larsen CD, Larsen MD, Ambrose T, Degano R, Gallo L, Cardo VA, Jr. Efficacy of a Prenatal Oral Health Program Follow-up with Mothers and their Children. The New York state dental journal. 2016;82(3):15-20. 
21. George A, Sousa MS, Kong AC, Blinkhorn A, Patterson Norrie T, Foster J, Dahlen HG, Ajwani S, Johnson M. Effectiveness of preventive dental programs offered to mothers by non-dental professionals to control early childhood dental caries: a review. BMC Oral Health. 2019;19(1):172.

22. George A, Dahlen HG, Blinkhorn A, Ajwani S, Bhole S, Ellis S, Yeo A, Elcombe E, Johnson M. Evaluation of a midwifery initiated oral health-dental service program to improve oral health and birth outcomes for pregnant women: A multi-centre randomised controlled trial. International Journal of Nursing Studies. 2018;82:49-57.

23. Vandenbroucke JP, von Elm E, Altman DG, Gøtzsche PC, Mulrow CD, Pocock SJ, Poole C, Schlesselman JJ, Egger M. Strengthening the Reporting of Observational Studies in Epidemiology (STROBE): explanation and elaboration. Int J Surg. 2014;12(12):1500-24.

24. .id community. Centre for Western Sydney: community profile [Internet]. 2021 [cited 2021 May 26]. Available from: https://profile.id.com.au/cws.

25. .id community. Greater Western Sydney: household income [Internet]. 2021 [cited 2021 May 26]. Available from: https://profile.id.com.au/cws/household-income.

26. Johnson M, George A, Dahlen H, Ajwani S, Bhole S, Blinkhorn A, Ellis S, Yeo A. The midwifery initiated oral health-dental service protocol: an intervention to improve oral health outcomes for pregnant women. BMC Oral Health. 2015;15(1):2.

27. Centre for Oral Health Strategy. Early Childhood Oral Health guidelines for child health professionals [Internet]. Sydney: NSW Health; 2014 [cited 2021 Mar 11]. Available from: https://www1.health.nsw.gov.au/pds/ActivePDSDocuments/GL2014_020.pdf.

28. Centre for Oral Health Strategy. Information for patients [Internet]. NSW Health; 2020 [cited 2020 Mar 11]. Available from: https://www.health.nsw.gov.au/oralhealth/pages/info-patients.aspx.

29. World Health Organization. Oral health surveys: basic methods. 5th ed: World Health Organization; 2013.

30. Ivoclar Vivadent. CRT ${ }^{\circledR}$ baceria: Caries risk test [Internet]. Schaan, Liechtenstein: Ivoclar Vivadent;; 2002 [cited 2021 Mar 11]. Available from: https://media.dentalcompare.com/m/25/Downloads/CRT\%20Bacteria\%20Scientific\%20Documentation.pdf.

31. Department of Health. Clinical practice guidelines: pregnancy care. Canberra: Australian Government Department of Health; 2019.

32. New York State Department of Health. Oral health care during pregnancy: practice guidelines [Internet]. New York: NYSDOH; 2006 [cited 2020 Apr 5]. Available from: https://www.health.ny.gov/publications/0824.pdf.

33. Berzinski M, Morawska A, Mitchell AE, Baker S. Parenting and child behaviour as predictors of toothbrushing difficulties in young children. International Journal of Paediatric Dentistry. 2020;30(1):75-84.

34. Boustedt K, Dahlgren J, Twetman S, Roswall J. Tooth brushing habits and prevalence of early childhood caries: a prospective cohort study. Eur Arch Paediatr Dent. 2020;21(1):155-9. 
35. Blinkhorn AS, Wainwright-Stringer YM, Holloway PJ. Dental health knowledge and attitudes of regularly attending mothers of high-risk, pre-school children. Int Dent J. 2001;51(6):435-8.

36. Kim J, Zhan L, Le T, Cheng J. Caregivers' Knowledge of Sugar and Control Over Children's Sugar Consumption. Pediatr Dent. 2019;41(3):191-9.

37. Feldens CA, Ardenghi TM, Cruz LN, Cunha Scalco GPd, Vítolo MR. Advising mothers about breastfeeding and weaning reduced pacifier use in the first year of life: a randomized trial. Community dentistry and oral epidemiology. 2013;41(4):317-26.

38. Australian Institute of Health Welfare. Child and teenager oral health and dental visiting: results from the National Dental Telephone Interview Survey 2010. Canberra: AlHW; 2013.

39. Peres MA, Ju X, Mittinty M, Spencer AJ, Do LG. Modifiable Factors Explain Socioeconomic Inequalities in Children's Dental Caries. J Dent Res. 2019;98(11):1211-8.

40. Finlayson TL, Asgari P, Dougherty E, Tadese BK, Stamm N, Nunez-Alvarez A. Child, caregiver, and family factors associated with child dental utilization among Mexican migrant families in California. Community Dent Health. 2018;35(2):89-94.

41. Unkel JH, Simon E, Kymer-Cheek E, Tucker J, Otero M, Berry E, Reinhartz J, Reinhartz D. Perinatal Oral Health Education and Compliance with the First Dental Visit. J Dent Child (Chic). 2020;87(3):153-8.

42. Yeap CK, Slack-Smith LM. Internet information on child oral health and the first dental visit. Aust Dent J. 2013;58(3):278-82.

43. Queensland Health. 30 percent of parents unaware of free dental services [Internet]. Queensland: Queensland Health; 2019 [cited 2021 Feb 11]. Available from: https://www.health.qld.gov.au/news-events/dohmedia-releases/releases/30-percent-of-parents-unaware-of-free-dental-services.

44. The Royal Children's Hospital Melbourne. Child oral health: habits in Australian homes [Internet]. Melbourne: RCH Melbourne; 2018 [cited 2021 Feb 11]. Available from: https://www.rchpoll.org.au/wpcontent/uploads/2018/03/NCHP10_Poll-report_Child-oral-health.pdf.

45. Department of Health. Maternal health and first 2000 days/women's health initiative [Internet]. 2019 [cited 2021 July 7]. Available from: https://www.health.gov.au/initiatives-and-programs/maternal-health-and-first-2000dayswomens-health-initiative.

\section{Tables}

Table 2: Oral health knowledge items and proportion of correct responses (CR) 
Having healthy baby teeth is not as important as having healthy permanent teeth

$192(94.1)$ because baby teeth will fall out (CR: False)

A good way to prevent cavities in children is to give sugary snacks only at meal times (CR: True)

It is ok to use the same spoon to taste baby's food (CR: False)

$44(21.6)$

Dental caries is a disease in which bacteria in your mouth use sugar to produce

$175(85.8)$

acid that breaks down your tooth enamel. (CR: True)

Early tooth decay appears as yellow areas that later break down into brownish

holes. (CR: True)

Undetected tooth decay can cause a child to suffer considerable pain and even

hospitalisation (CR: True)

Children of mothers who have tooth decay are more likely to get tooth decay (CR:

True)

Cheese is a snack that is least likely to cause decay (CR: True)

It is safe to put baby to bed with a bottle of milk (CR: False)

A pea sized amount of toothpaste should be used when brushing children's teeth

(CR: True)

Children should be assisted in brushing till the age of 8 years (CR: True)

Parents should regularly perform a 'lift the lip' check on their child (CR: True)

Tooth decay in early childhood is: (CR: The single most common chronic

childhood disease)

Untreated tooth decay can lead to: (CR: All of the above)

Which of the following drinks do not cause tooth decay? (CR: Water)

What are factors that might increase the risk of tooth decay?

Taking too much sugary food or drinks (CR: True)

Not brushing teeth with fluoride toothpaste in the morning and at night

(CR: True)

Eating or drinking too frequently (CR: False)

Not rinsing after meals (CR: True)

Lack of calcium (CR: False)

Breastfeeding beyond 12 months of age (CR: False)

Discontinuing bottle feeding before 12 months (CR: False)

Sipping from a bottle/cup throughout the day with something sweet in it

(CR: True)

None of the above (CR: False)

When should you start brushing a child's teeth? (CR: When the first tooth appears)

Before infant's teeth appear, parents should: (CR: Clean an infant's gums with a damp washcloth after meals and before bed)

Tooth decay in early childhood is caused by a combination of many factors that include the following: (CR: All of the above)

Which is not a risk factor for tooth decay in early childhood? (CR: Sleeping with a bottle filled with plain water)

A child's first dental visit should be: (CR: At one year old)

$199(98.0)$

192(94.1)

202(99.0)

$147(72.1)$

$143(70.1)$

$180(88.2)$

202(99.0)

191(93.6)

$145(71.4)$

142(77.6)

189(92.6)

203(99.5)

203(99.5)

201(98.5)

77(37.7)

168(82.4)

22(10.8)

155(76.0)

176(86.3)

177(86.8)

203(99.5)

156(76.5)

116(56.9)

201(98.5)

204(100.0)

63(30.9)

\section{Table 3: Child preventative dental behaviours as reported by mothers}




\begin{tabular}{|c|c|}
\hline Preventative dental behaviour & $\mathrm{n}(\%)$ \\
\hline Dental visits & \\
\hline Sought dental professional for oral health problems/concerns & $25(49.0)$ \\
\hline Hospitalisation related to dental problems & $4(2.0)$ \\
\hline Child regularly visits dentist every year & $92(46.0)$ \\
\hline Last visit within past 12 months & $73(36.3)$ \\
\hline Age of first dental visit & \\
\hline Under one year old & $5(3.8)$ \\
\hline One year & $26(19.8)$ \\
\hline Two years & $38(29.0)$ \\
\hline Three years & $37(28.2)$ \\
\hline Four years & $5(3.8)$ \\
\hline Never & $20(15.3)$ \\
\hline Setting of child's last dental visit & \\
\hline Private practice & $76(65.0)$ \\
\hline Government dental service & $22(18.8)$ \\
\hline School dental service & $2(1.7)$ \\
\hline Other & $12(10.3)$ \\
\hline Don't know & $5(4.3)$ \\
\hline Received information about child oral health & $119(61.7)$ \\
\hline Received ECOH program & $3(1.6)$ \\
\hline Oral hygiene & \\
\hline Frequency of tooth brushing with toothpaste & \\
\hline Less than once a day & $14(6.9)$ \\
\hline Once a day & $97(47.8)$ \\
\hline Twice a day & $90(44.3)$ \\
\hline More than twice a day & $2(1.0)$ \\
\hline Type of toothpaste used & \\
\hline Standard fluoride toothpaste & $20(9.9)$ \\
\hline Children's toothpaste & $173(85.2)$ \\
\hline Non-fluoride toothpaste & $6(3.0)$ \\
\hline None & $4(2.0)$ \\
\hline Amount of toothpaste used & \\
\hline Less than a pea sized amount & $51(25.6)$ \\
\hline A pea sized amount (recommended) & $135(67.8)$ \\
\hline More than a pea sized amount & $13(6.5)$ \\
\hline Assists child with tooth brushing & 199(98.0) \\
\hline Dietary and other habits & \\
\hline Consumes juice at least once per day & $56(27.6)$ \\
\hline Consumes soft drink at least once per day & $6(3.0)$ \\
\hline Consumes biscuits, cakes donuts or muesli bars at least once per day & $51(25.1)$ \\
\hline Consumes confectionary at least once per day & $22(10.9)$ \\
\hline Drinks from bottle at least sometimes & $35(17.2)$ \\
\hline Always drinks from regular cup & $139(68.1)$ \\
\hline Child currently using bottle & $64(31.4)$ \\
\hline History of regular pacifier use & $85(41.7)$ \\
\hline Shares eating utensils with child & $123(60.3)$ \\
\hline Used mouth to clean pacifier for child & $26(12.7)$ \\
\hline Coated pacifier or teat with sweet substances & $7(3.4)$ \\
\hline Given a bottle when lying down to sleep & $82(40.2)$ \\
\hline
\end{tabular}

\section{Supplementary Files}

This is a list of supplementary files associated with this preprint. Click to download. 
- Supplementary1.docx

- Supplementary2.docx

- Supplementary3.docx 